\title{
STRUCTURAL ANALYSIS OF TECHNICAL EQUIPMENT FOR SETTING UP ROW CROPS AND APPLYING DEGRADABLE FILM
}

\author{
Gheorghe Gabriel, Catalin Persu, Marin Eugen, Manea Dragos \\ National Institute of Research - Development for Machines and \\ Installations Designed to Agriculture and Food Industry, Romania \\ gabrielvalentinghe@yahoo.com
}

\begin{abstract}
The article presents the structural analysis of technical equipment for setting up row crops and applying a degradable film including the calculation of resistance, expression of the interaction forces with the ground, tractor coupling modeling and the main results used in design. The article includes elements of optimization of the machine structure and relevant directions aimed to improve the working qualities and constructive behaviour of tractor aggregates and technical equipment. The multifunctional equipment is analysed within this paper. In order to minimize soil degradation, the technical equipment can perform concurrently: weeding crop sowing and application of the degradable film. As it eliminates the stage of the degradable film tightening from field, thus reducing the number of passages, it results in lower costs and high earnings, by improving, at the same time, the soil features and environment protection. By a single passage, the multifunctional equipment performs: 2 rows of sowing at depth $(20-120 \mathrm{~mm})$, applies the degradable film on the width $(800-1200 \mathrm{~mm})$ and optional tape irrigation under the film.
\end{abstract}

Keywords: simulation, structural analysis, optimization.

\section{Introduction}

Sowing is made at $70 \mathrm{~cm}$ distance between the rows and 5-8 $\mathrm{cm}$ depth, ensuring $15-25 \mathrm{~kg}$ of seeds per hectare. The technical equipment undergoing the structural analysis presented in Fig. 1 performs, in a single passage, the establishment of weeding crops simultaneously with covering the seed row with a degradable film, which prevents weeds from coming out of the ground on the lane corresponding to the plant row [1].

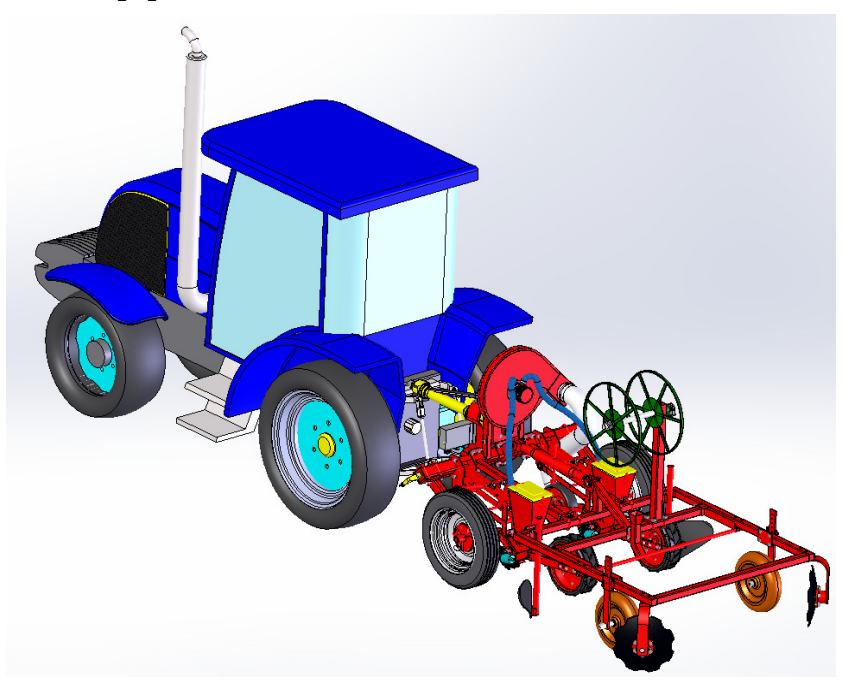

Fig. 1. Technical equipment undergoing structural analysis coupled to the tractor

In this article we will calculate the fatigue of the three-point hitch due to the equipment lifting and lowering at each row end. In materials science, fatigue is weakening of a material caused by repeatedly applied loads. It is progressive and localized structural damage that occurs when a material is subjected to cyclic loading. The nominal maximum stress values that cause such damage may be much less than the strength of the material typically quoted as the ultimate tensile stress limit, or the yield stress limit. Fatigue occurs when a material is subjected to repeated loading and unloading. If the loads are above a certain threshold, microscopic cracks will begin to form at the stress concentrators such as the surface. Eventually a crack will reach a critical size, the crack will propagate suddenly, and the structure will fracture. The shape of the structure will significantly affect the fatigue life; square holes or sharp corners will lead to elevated local stresses where fatigue cracks can initiate. Round holes and smooth transitions or fillets will therefore increase the fatigue strength of the structure [2]. 


\section{Materials and methods}

In the first phase, we calculate the number of lifting-lowering actions at the row end for several working methods of the equipment during sowing works. The calculation will be made for a working surface with the length of $500 \mathrm{~m}$, resulting an average of working lengths of the parcels in Romania and the equipment working width is $0.7 \mathrm{~m}$. Life, according to the sowing machine manufacturers, is eight years, and a sowing campaign has optimum soil conditions for seed germination 5-7 days per year, in one day work can be made for 8-12 hours and sowing can be done at speeds of 5, 6, $7 \mathrm{~km} \cdot \mathrm{h}^{-1}$.

The frame structure is not among the equipment elements that fail first, but the most stressed elements and which fail the first can be replaced more easily than the structure frame. Therefore, we need to make a fatigue analysis of the frame to observe the equipment life and to optimize the frame, respectively, the choice of its building material.

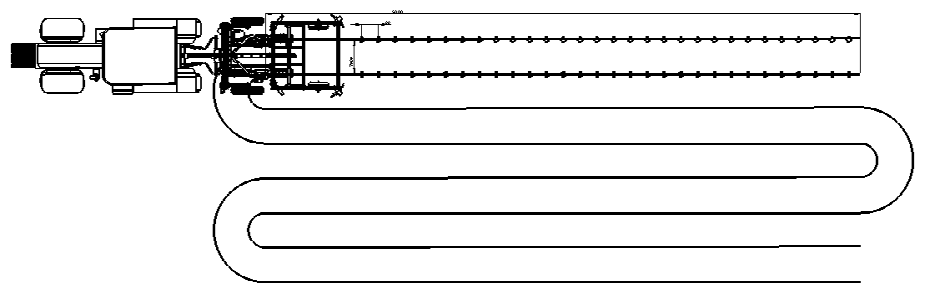

Fig. 2. Equipment sowing scheme

For the speeds of $5 \mathrm{~km} \cdot \mathrm{h}^{-1}, 6 \mathrm{~km} \cdot \mathrm{h}^{-1}$, and $7 \mathrm{~km} \cdot \mathrm{h}^{-1}$ the $n$-number of lifting-lowering (cycles) in one hour is calculated (1); we do not take into account the equipment speed on the return way:

$$
n=\frac{v}{l}, \text { cycles } \cdot \mathrm{h}^{-1}
$$

$5000 \mathrm{~m} \cdot \mathrm{h}^{-1} / 500 \mathrm{~m}=10$ cycles $\cdot \mathrm{h}^{-1}$

$6000 \mathrm{~m} \cdot \mathrm{h}^{-1} / 500 \mathrm{~m}=12$ cycles $\cdot \mathrm{h}^{-1}$;

$7000 \mathrm{~m} \cdot \mathrm{h}^{-1} / 500 \mathrm{~m}=14$ cycles $\cdot \mathrm{h}^{-1}$.

The number of cycles differs depending on the working plot length, but an average of $500 \mathrm{~m}$ length was considered.

Table 1

Equipment working methods during sowing works

\begin{tabular}{|c|c|c|}
\hline $\begin{array}{c}\text { Optimal conditions for } \\
\text { germination, days per year }\end{array}$ & $\begin{array}{c}\text { Effective working time, } \\
\mathbf{h} \cdot \text { day }^{-1}\end{array}$ & $\begin{array}{c}\text { Number of lifting-lowering } \\
\text { actions caused by the } \\
\text { working speed, cycles }\end{array}$ \\
\hline 5 & 8 & 10 \\
\hline 6 & 10 & 12 \\
\hline 7 & 12 & 14 \\
\hline
\end{tabular}

Number of cycles per year in different working methods minimum and maximum:

Minimum number of cycles per year: 5 days $\cdot$ year $^{-1} \times 8 \mathrm{~h} \cdot$ day $^{-1}$ x 10 cycles $\cdot \mathrm{h}^{-1}=400$ cycles $\cdot$ year $^{-1}$;

Maximum number of cycles per year: 7 days $\cdot$ year $^{-1}$ x $12 \mathrm{~h} \cdot$ day $^{-1}$ x 14 cycles $\cdot \mathrm{h}^{-1}=1176$ cycles $\cdot$ year $^{-1}$.

To calculate the life of the equipment frame until cracks appear in its structure we used SolidWorks program, Simulation module to perform calculation of the structure fatigue.

To perform the calculation we will simulate the equipment lifting in the first phase, static, then the fatigue study.

The input data to perform the static analysis are the following:

1. All assembly components are made of S355JR. Assign S355JR to All Components, in the SolidWorks Simulation Manager tree, right-click the Parts folder and click Apply Material to All. The mechanical and physical properties of S355JR appear in the table to the right as shown in Figure 3. 


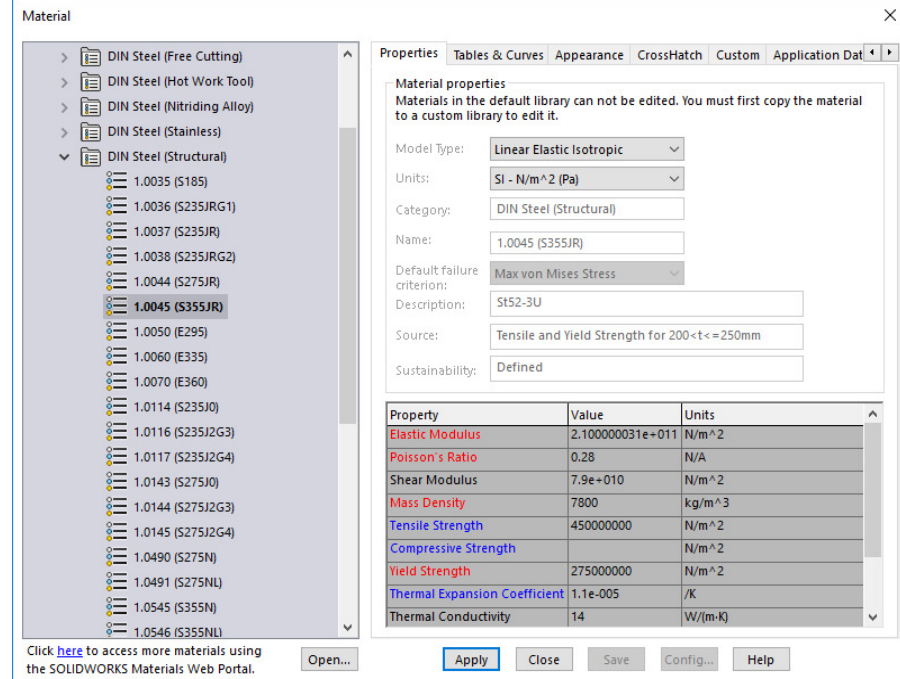

Fig. 3. Mechanical and physical properties of S355JR

2. Fixing the structure in the tractor's three attaching points will be made as shown in Fig. 4. In the Simulation study tree, right-click the Fixtures folder and click Fixed Geometry. The Fixture Property Manager appears. Make sure that Type is set to Fixed Geometry. In the graphics area, click of the three clamping bolts, indicated in Figure 4.

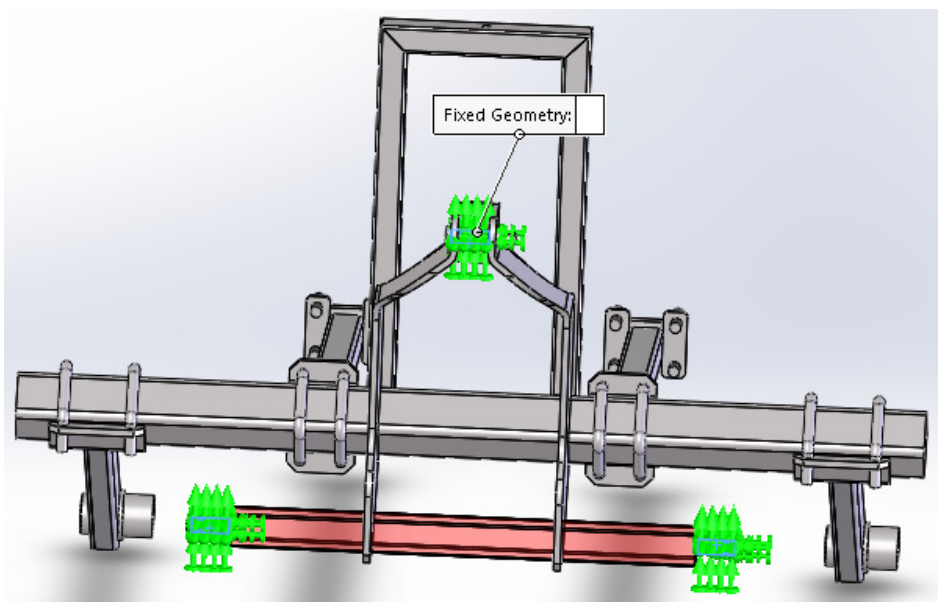

Fig. 4. Fixed Geometry of the structure

3. On this frame, we applied the 3 acting forces:

- The first one is the weight of the equipment in the back for the application of photobiodegradable mulch film according to Fig. 1, of $1300 \mathrm{~N}$; we exemplify its application in Fig. 5.a;

- The second one is the weight of the wheels, of $220 \mathrm{~N}$ per wheel; we exemplify its application in Fig. 5.b;

- The third one is the weight of the exhauster, of $350 \mathrm{~N}$; we exemplify its application in Fig. 5.c.

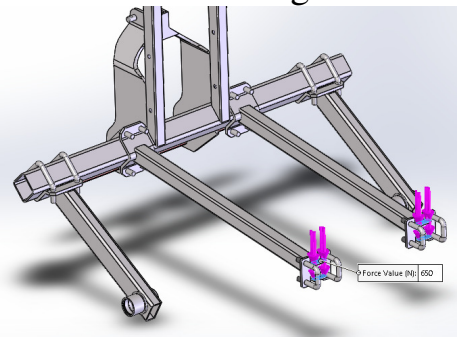

a)

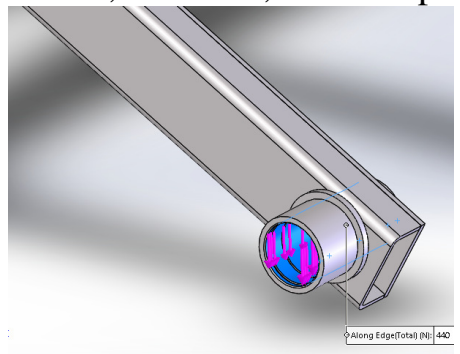

b)

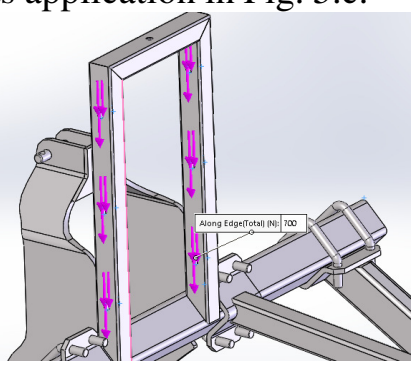

c)

Fig. 5. Applying the forces acting on the frame 
To check a structure stressed by shock, first we calculate the static unitary stress, static deformation (produced by the same load, if applied slowly) and impact multiplier; the dynamic unitary stress and dynamic deformation are obtained by multiplying the static unitary stress, respectively static deformation by the impact multiplier.

In our case there is a sudden application of a stress, without the height of fall $(\mathrm{h}=0)$, and the impact multiplier is calculated according to the equation (2).

$$
\Psi=1+\sqrt{1+\frac{2 h}{\delta_{s}}}
$$

From equation (2) results $\psi=2$, which shows that the effect of suddenly applied stress is two times higher than the effect of a static stress applied, namely, with the value increasing slowly from zero to the final value; sudden application of stress is also a case of shock. The forces introduced in the calculation were multiplied by two, after measuring masses and calculating the weights. After creating the mesh, the simulation will run and the results will be interpreted [3].

\section{Results and discussion}

The von Mises yield criterion suggests that the yielding of materials begins when the second deviatoric stress invariant reaches a critical value. It is part of a plasticity theory that applies best to ductile materials, such as metals. Prior to yield, material response can be assumed to be anything, i.e. nonlinear elastic, viscoelastic or simply linear elastic.

In materials science and engineering the von Mises yield criterion can be also formulated in terms of the von Mises stress or equivalent tensile stress, a scalar stress value that can be computed from the Cauchy stress tensor. In this case, a material is said to start yielding when its von Mises stress reaches a critical value known as the yield strength, like in Figure 6 [4].

According to the simulation, the structure starts yielding because von Mises stress reaches a critical value known as the yield strength of material as we see in Figure 3.

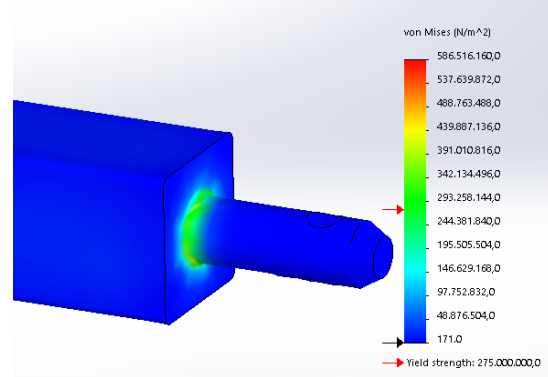

Fig. 6. Von Mises results of simulation

In the simulation we can also observe the structure displacements due to forces applied with shock, the biggest displacement being registered when the film applying equipment, showed in Fig. 7, is attached in the back. We can see a maximum displacement of approx. $11 \mathrm{~mm}$, which in time will damage the structure; this will be observed in the calculation of the fatigue.

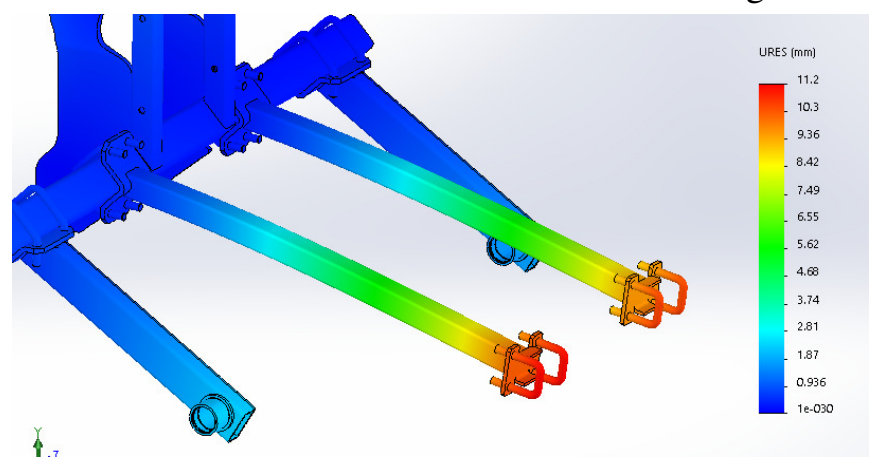

Fig. 7. Displacement of structure elements 
In this study we can also see deformation as in Fig. 8. In materials science, deformation refers to any changes in the shape or size of an object due to an applied force (the deformation energy in this case is transferred through work). The biggest deformations occur at the coupling pipe of the equipment attached in the back, Fig. 8.a, and at the coupling bolt, Fig.8.b.

a)

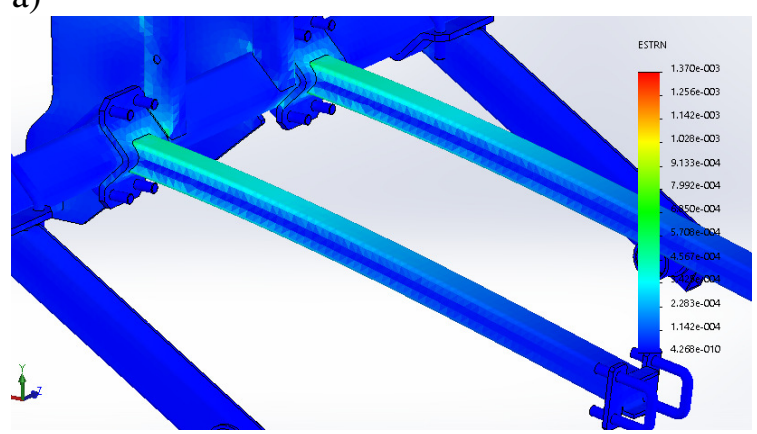

b)

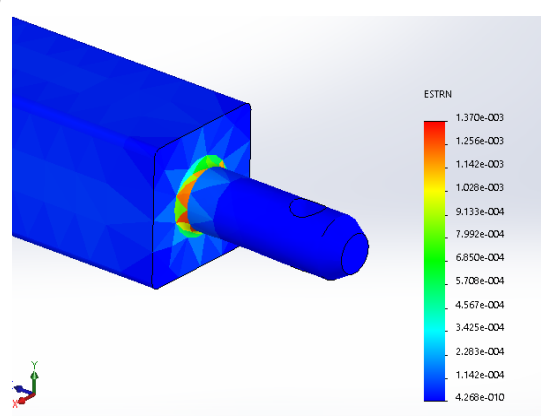

Fig. 8. Deformations of structure elements

After the static simulation, we made the calculation of fatigue, Fig. 9, to see at how many cycles (lifting-lowering at the row end) the equipment coupling to the tractor resists and to determine the structure life until repairs will be necessary. The frame is not the first element to fail in the case of agricultural equipment, but those failing first can usually be replaced.

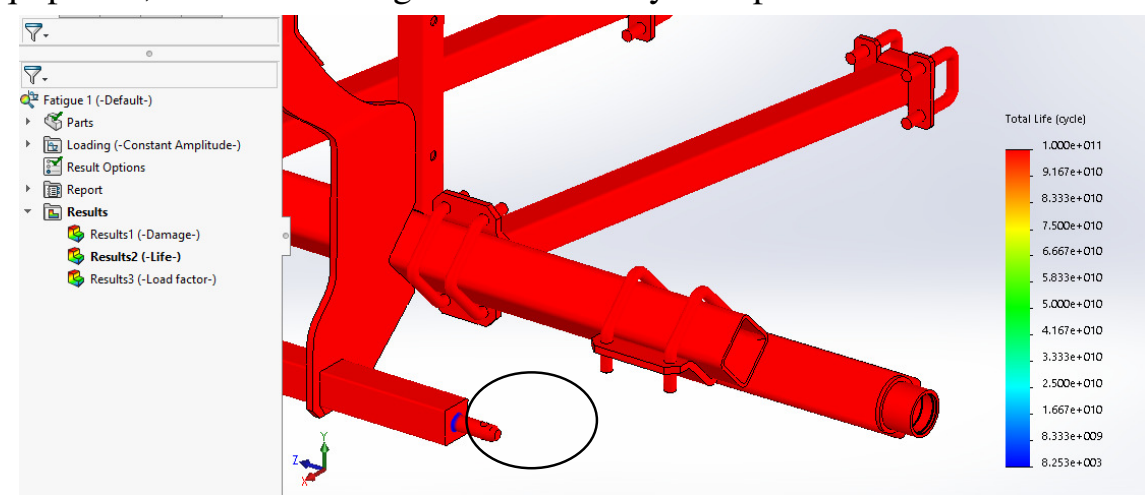

Fig. 9. Results of fatigue calculation

As it is shown in the figure above, at 8235 cycles cracks appear at the coupling bolt and this can be used to determine the frame life. According to the agricultural equipment manufacturers, the sowing machines life is 8 years.

\section{Conclusions}

1. According to the theoretical simulation cracks in the coupling bolt appear after 8235 cycles. Due to the calculations made in SolidWorks Simulation, we can determine, depending on the working conditions in Table 1, how long it takes for cracks to appear in the coupling bolt.

For example:

Minimum number of cycles per year: 5 days $\cdot$ year $^{-1}$ x $8 \mathrm{~h} \cdot$ day $^{-1}$ x 10 cycles $\cdot \mathrm{h}^{-1}=400$ cycles $\cdot$ year $^{-1}$, will generate the sowing machine frame life of 8253 cycles $\div 400$ cycles $\cdot$ year $^{-1}=20$ years (life). If the sowing machine is used intensively, maximum number of cycles per year: 7 days $^{-y^{2} \mathrm{r}^{-1} \mathrm{x}}$ $12 \mathrm{~h} \cdot \mathrm{day}^{-1}$ x 14 cycles $\cdot \mathrm{h}^{-1}=1176$ cycles $\cdot$ year $^{-1}$, we will have a sowing machine frame life of 8253 cycles $\div 1176$ cycles $\cdot$ year $^{-1}=7$ years (life).

2. After the execution of the equipment, it will be placed on the test bench in accelerated mode and we will compare the theoretical results of SoldikWorks Simulation, in order to validate them, with the results from testing in accelerated mode. 


\section{Acknowledgment}

The work has been funded by the Ministry of National Education and Research through the National Agency for Scientific Research, within the project entitled "Innovative technology for weeding crop establishment through mulching using degradable film”, PN 16240402.

\section{References}

1. Bîlteanu G. Plant Science, Cereș Publishing House, Bucharest, vol.1, pp. 220-343;

2. Stephens R.I. Fuchs, H.O. Metal Fatigue in Engineering (Second ed.). John Wiley \& Sons, Inc. 2001, p. 69.

3. Drobota V., Dorobantu M., Atanasiu M. Materials resistance, Didactic and Pedagogic Publishing House, Bucharest, 1972.

4. Malvern, L.E. Introduction to the Mechanics of a Continuous Medium, Prentice Hall, 1969

5. Lubliner J. Plasticity Theory. Dover Publications, 2008. ISBN 0-486-46290-0. 